\title{
BMJ Open Vitamin D insufficiency in COVID-19 and influenza $A$, and critical illness survivors: a cross-sectional study
}

\author{
Emma A Hurst, ${ }^{1,2}$ Richard J Mellanby, ${ }^{1}$ Ian Handel, ${ }^{1}$ David M Griffith (D) , ${ }^{3}$ \\ Adriano G Rossi, ${ }^{4}$ Timothy S Walsh, ${ }^{4,5}$ Manu Shankar-Hari, ${ }^{6,7}$ Jake Dunning, ${ }^{8}$ \\ Natalie Z Homer, ${ }^{2}$ Scott G Denham, ${ }^{2}$ Kerri Devine, ${ }^{2}$ Paul A Holloway, ${ }^{9}$ \\ Shona C Moore, ${ }^{10}$ Ryan S Thwaites, ${ }^{11}$ Romit J Samanta, ${ }^{12}$ \\ Charlotte Summers (D) , ${ }^{12}$ Hayley E Hardwick, ${ }^{10}$ Wilna Oosthuyzen, ${ }^{13}$ \\ Lance Turtle, ${ }^{10,14}$ Malcolm G Semple, ${ }^{10,15}$ Peter J M Openshaw, ${ }^{11}$ \\ J Kenneth Baillie, ${ }^{5,13}$ Clark D Russell (D) , ${ }^{4,13}$ ISARIC4C Investigators
}

To cite: Hurst EA, Mellanby RJ, Handel I, et al. Vitamin D insufficiency in COVID-19 and influenza $\mathrm{A}$, and critical illness survivors: a crosssectional study. BMJ Open 2021;11:e055435. doi:10.1136/ bmjopen-2021-055435

- Prepublication history and additional supplemental material for this paper are available online. To view these files, please visit the journal online (http://dx.doi.org/10.1136/ bmjopen-2021-055435).

Received 13 July 2021 Accepted 30 September 2021

Check for updates

(C) Author(s) (or their employer(s)) 2021. Re-use permitted under CC BY. Published by BMJ.

For numbered affiliations see end of article.

Correspondence to Dr Clark D Russell; clark.russell@ed.ac.uk

\section{ABSTRACT}

Objectives The steroid hormone vitamin $D$ has roles in immunomodulation and bone health. Insufficiency is associated with susceptibility to respiratory infections. We report 25-hydroxy vitamin $\mathrm{D}(25(\mathrm{OH}) \mathrm{D})$ measurements in hospitalised people with COVID-19 and influenza A and in survivors of critical illness to test the hypotheses that vitamin D insufficiency scales with illness severity and persists in survivors.

Design Cross-sectional study.

Setting and participants Plasma was obtained from 295 hospitalised people with COVID-19 (International Severe Acute Respiratory and emerging Infections Consortium (ISARIC)/WHO Clinical Characterization Protocol for Severe Emerging Infections UK study), 93 with influenza A (Mechanisms of Severe Acute Influenza Consortium (MOSAIC) study, during the 2009-2010 H1N1 pandemic) and 139 survivors of non-selected critical illness (prior to the COVID-19 pandemic). Total 25(OH)D was measured by liquid chromatography-tandem mass spectrometry. Free $25(\mathrm{OH}) \mathrm{D}$ was measured by ELISA in COVID-19 samples.

Outcome measures Receipt of invasive mechanical ventilation (IMV) and in-hospital mortality.

Results Vitamin D insufficiency (total 25(OH)D 25$50 \mathrm{nmol} / \mathrm{L})$ and deficiency $(<25 \mathrm{nmol} / \mathrm{L})$ were prevalent in COVID-19 (29.3\% and 44.4\%, respectively), influenza A (47.3\% and $37.6 \%)$ and critical illness survivors $(30.2 \%$ and $56.8 \%$ ). In COVID-19 and influenza A, total 25(OH) $\mathrm{D}$ measured early in illness was lower in patients who received IMV (19.6 vs $31.9 \mathrm{nmol} / \mathrm{L}(\mathrm{p}<0.0001)$ and 22.9 vs $31.1 \mathrm{nmol} / \mathrm{L}$ ( $p=0.0009$ ), respectively). In COVID-19, biologically active free $25(\mathrm{OH}) \mathrm{D}$ correlated with total $25(\mathrm{OH}) \mathrm{D}$ and was lower in patients who received IMV, but was not associated with selected circulating inflammatory mediators.

Conclusions Vitamin D deficiency/insufficiency was present in majority of hospitalised patients with COVID-19 or influenza $A$ and correlated with severity and persisted in critical illness survivors at concentrations expected to disrupt bone metabolism. These findings support early supplementation trials to determine if insufficiency is

\section{Strengths and limitations of this study}

- Liquid chromatography-tandem mass spectrometry was used to quantify 25 -hydroxy vitamin $D(25(\mathrm{OH})$ D) in plasma samples from well-characterised hospitalised people with COVID-19 and influenza A and survivors of non-selected critical illness.

- Biologically active free 25(OH)D was measured by ELISA in COVID-19 plasma samples for the first time.

- Samples from people with COVID-19 and influenza A were obtained early in the course of the disease.

- Binary logistic regression multivariable models were used to assess the association of plasma $25(\mathrm{OH})$ D concentration with outcomes in COVID-19 and influenza $A$, correcting for other known relevant covariates.

- The observational nature of the study means it is not known whether vitamin D status led to poor clinical outcome or was a consequence of illness severity.

causal in progression to severe disease, and investigation of longer-term bone health outcomes.

\section{INTRODUCTION}

Vitamin D metabolites contribute to bone metabolism, calcium homeostasis and immunomodulation. Vitamin D is a steroid pre-pro-hormone which is converted to the main circulating form 25-hydroxy vitamin D $(25(\mathrm{OH}) \mathrm{D})$, and subsequently to the active hormone 1,25 dihydroxy vitamin $\mathrm{D}$. This second activation step occurs in the kidney, modulated by parathyroid hormone (PTH), for 'endocrine' calciotropic effects, and also under local control within extra-renal tissues, including immune cells, for direct action. These 'intracrine' actions on immune cells mediate antimicrobial and anti-inflammatory effects. ${ }^{1}$ The majority of $25(\mathrm{OH}) \mathrm{D}$ circulates 
bound to proteins, principally vitamin $\mathrm{D}$ binding protein $(85 \%-90 \%)$, and the relatively small unbound ('free') fraction is available to immune cells. ${ }^{2}$

In the context of infectious diseases, vitamin D insufficiency (routinely determined by total $25(\mathrm{OH}) \mathrm{D}$ measurement) is associated with increased incidence and severity of respiratory tract infections, ${ }^{3-5}$ including COVID-19. ${ }^{67}$ A geographical association between vitamin $\mathrm{D}$ deficiency prevalence and COVID-19 incidence and mortality has been reported. ${ }^{8}$ Free $25(\mathrm{OH}) \mathrm{D}$ has not yet been investigated in COVID-19, but this is required to fully understand vitamin $\mathrm{D}$ status during acute illness and any associations with systemic inflammation. ${ }^{9}$ Clinical trials of vitamin D supplementation in respiratory diseases have returned mixed results. ${ }^{10-13}$ Potential beneficial effects of vitamin D supplementation may be pathogen-specific and dependent on timing and route of administration. In addition to an interest in modifying acute illness outcomes, longerterm effects on bone health warrant consideration as critical illness is associated with loss of bone mineral density after recovery. ${ }^{14}$

In this cross-sectional study, we report measurements of total and free $25(\mathrm{OH}) \mathrm{D}$ in hospitalised people with COVID-19 and total 25(OH)D in hospitalised people with influenza A and survivors of critical illness. We use these three data sets to test the hypotheses that vitamin D insufficiency in severe respiratory virus infections scales with severity and persists in survivors of critical illness.

\section{METHODS \\ Patients and sampling \\ COVID-19}

The International Severe Acute Respiratory and emerging Infections Consortium (ISARIC) WHO Clinical Characterization Protocol for Severe Emerging Infections in the UK (CCP-UK) is an ongoing prospective cohort study of hospitalised people with COVID-19, which is recruiting in 308 hospitals in England, Scotland, Wales and Northern Ireland (National Institute for Health Research Clinical Research Network Central Portfolio Management System ID: 14152), delivered by the ISARIC Coronavirus Clinical Characterisation Consortium (ISARIC4C) investigators. The protocol, revision history, case report form and consent forms are available online at isaric4c.net. The ISARIC/WHO CCP-UK study was registered at https:// www.isrctn.com/ISRCTN66726260 and designated an Urgent Public Health Research Study by the National Institute for Health Research UK. A prespecified case report form was used to collect data on patient characteristics, medical interventions received, and outcomes, as previously reported. ${ }^{15}$

\section{Influenza A}

Hospitalised patients with influenza A were recruited between 2009 and 2010 (the first and second H1N1 pandemic waves) and 2011 (the first postpandemic season) by the Mechanisms of Severe Acute Influenza
Consortium (MOSAIC) investigators, as previously reported. ${ }^{16}$

Non-selected critical illness survivors

We include a post-hoc analysis of the RECOVER (Evaluation of a Rehabilitation Complex Intervention for Patients Following Intensive Care Discharge) trial of intensive rehabilitation after critical illness. ${ }^{17}$ Full eligibility criteria have been published previously; briefly, adults who had received invasive mechanical ventilation (IMV) for at least 48 hours and were considered well enough for discharge from the intensive care unit (ICU) were recruited. Patients gave additional consent for participation in a biomarker substudy and blood samples were collected at ICU discharge. ${ }^{18}$

All participants gave informed consent.

\section{Patient and public involvement}

There was no patient or public involvement in this study.

\section{LC-MS/MS methods for total 25(OH)D analysis}

EDTA plasma concentrations (on samples obtained on the day of enrolment to the study) of $25(\mathrm{OH}) \mathrm{D}_{2}$ and $25(\mathrm{OH})$ $\mathrm{D}_{3}$ isoforms were measured by liquid chromatographytandem mass spectrometry (LC-MS/MS) and summed to derive the total $25(\mathrm{OH}) \mathrm{D}$ concentrations presented in the results. For patients with COVID-19 and critical illness survivors, analysis was performed by the Vitamin D Animal Laboratory using an assay which has been certified as proficient by the international Vitamin D External Quality Assessment Scheme and described in detail in an earlier manuscript, using $200 \mu \mathrm{L}$ plasma. ${ }^{19}$ The interassay precision (coefficient of variation, GV) of this method was $<11.5 \%$ for both $25(\mathrm{OH}) \mathrm{D}_{2}$ and $25(\mathrm{OH}) \mathrm{D}_{3}$ analytes (online supplemental table 1). For patients with influenza A, analysis was performed using another LC-MS/ MS method at a separate clinical biochemistry laboratory. The interassay precision of this method was $<11 \%$ for $25(\mathrm{OH}) \mathrm{D}_{2}$ and $<10 \%$ for $25(\mathrm{OH}) \mathrm{D}_{3}$ (online supplemental table 1). Full LC-MS/MS methods are presented in online supplemental table 1.

\section{Definition of vitamin D status}

In addition to the absolute total $25(\mathrm{OH}) \mathrm{D}$ concentration, the relationship between vitamin $\mathrm{D}$ status and outcomes is often explored using a total $25(\mathrm{OH}) \mathrm{D}$ cutoff of $50 \mathrm{nmol} / \mathrm{L}$ to define populations that are vitamin D sufficient. ${ }^{20}$ In this study, total $25(\mathrm{OH}) \mathrm{D}>50 \mathrm{nmol} / \mathrm{L}$ is reported as 'sufficient', $25-50 \mathrm{nmol} / \mathrm{L}$ as 'insufficient' and $<25 \mathrm{nmol} / \mathrm{L}$ as 'deficient' (see online supplemental methods).

\section{Free 25(OH)D ELISA}

Free $25(\mathrm{OH})$ D was measured using the Free $25 \mathrm{OH}$ Vitamin D ELISA (DIAsource ImmunoAssays SA, Belgium), following the manufacturer's instructions, using $10 \mu \mathrm{L}$ of plasma. Absorbance was measured at $450 \mathrm{~nm}$ against a reference filter set at $630 \mathrm{~nm}$ using the Tecan Sunrise Microplate Reader (Tecan). GraphPad Prism (V.7.0e for 
MacOS X) was used to perform a four-parameter logistic function to create the calibration curve in order to read the mean concentration of duplicate samples. The lower limit of detection (LLOD) of the assay was $2.4 \mathrm{pg} / \mathrm{mL}$. The intra-assay repeatability (CV) was $\leq 5.5 \%$ across three concentrations (low, mid and high concentrations on the standard curve) and the interassay precision (CV) was $<6.5 \%$ across the three concentrations, calculated based on Clinical and Laboratory Standards Institute EP05-A3 and reported in the manufacturer's guidelines. Two control samples (low and high concentrations) were analysed in each batch in duplicate and data were only reported for the batch if the results of the controls were within the acceptance range outlined on each control sample vial. Each calibrator, control and patient sample were assessed in duplicate and the results only reported if the $\mathrm{CV}$ of the replicates was $<10 \%$.

\section{Statistical analysis}

For univariable analyses, the Shapiro-Wilk test was used to test for normal data distribution, and then appropriate tests, specified in the text, were used for comparisons. Associations between covariates and outcomes in COVID-19 and influenza A were assessed with binary logistic regression multivariable models. Sex, age, illness duration at time of sampling and comorbidity count were chosen as covariates. The comorbidity count was derived from the same comorbidities (table 1) from the two cohorts. To allow for potential non-linear relationship between predictors and the probability of an outcome, the models included smoothed thin plate regression spline terms for age, illness duration at time of sampling, comorbidity count and $25(\mathrm{OH}) \mathrm{D}$ concentrations. Multivariable models were estimated using the $\operatorname{gam}($ ) function

\begin{tabular}{|c|c|c|c|c|}
\hline Characteristics & $\begin{array}{l}\text { COVID-19 } \\
(n=259)\end{array}$ & $\begin{array}{l}\text { Influenza A } \\
(\mathrm{n}=93)\end{array}$ & $\begin{array}{l}\text { Critical illness survivors } \\
(n=139)\end{array}$ & P value* \\
\hline \multicolumn{5}{|l|}{ Demographics } \\
\hline Age at admission, years $\dagger$ & $63(52-73)$ & $43(29-50)$ & $63(53-70)$ & $<0.0001$ \\
\hline Male sex & $175(67.6)$ & $47(50.5)$ & $85(61.2)$ & 0.01 \\
\hline $\begin{array}{l}\text { Day of illness at the time of } \\
\text { sampling }\end{array}$ & $10(6-16)$ & $7(4-11)$ & $11(6-18) \ddagger$ & $<0.001 \S$ \\
\hline \multicolumn{5}{|l|}{ Comorbidities } \\
\hline Diabetes mellitus & $66(25.5)$ & $10(10.8)$ & $23(16.5)$ & 0.005 \\
\hline Chronic cardiac disease & $57(22.4)$ & $17(18.3)$ & $15(10.8)$ & 0.02 \\
\hline Obesity, clinician-defined & $44(18.7)$ & $23(24.7)$ & $28(20.1)$ & 0.3 \\
\hline Asthma & $41(16.1)$ & $33(35.5)$ & $26(18.7)$ & 0.0002 \\
\hline Chronic lung disease, not asthma & $35(13.8)$ & $12(12.9)$ & $24(17.3)$ & 0.5 \\
\hline Chronic kidney disease & $25(9.9)$ & $4(4.3)$ & NA & 0.1 \\
\hline Neoplasia & $14(5.6)$ & $9(9.7)$ & NA & 0.2 \\
\hline Moderate or severe liver disease & $3(1.2)$ & $4(4.3)$ & NA & 0.08 \\
\hline \multicolumn{5}{|l|}{ Illness severity } \\
\hline Admission to critical care & $106(40.9)$ & $32(34.4)$ & $139(100)$ & $0.3 \S$ \\
\hline Invasive mechanical ventilation & $67(25.9)$ & $29(31.2)$ & $139(100)$ & $0.3 \S$ \\
\hline In-hospital mortality & $52(20.1)$ & 12 (12.9) & 4 (2.9)ף & $0.2 \S$ \\
\hline \multicolumn{5}{|l|}{ Total plasma $25(\mathrm{OH}) \mathrm{D}$} \\
\hline Median (IQR), nmol/L & $28.5(17.1-51.9)$ & $28.1(20.2-37.9)$ & $23.7(15.3-34.9)$ & 0.01 \\
\hline \multicolumn{5}{|l|}{ Status } \\
\hline Sufficient $(>50 \mathrm{nmol} / \mathrm{L})$ & $68(26.3)$ & $14(15.1)$ & $18(12.9)$ & 0.0002 \\
\hline Insufficient (25-50 nmol/L) & $76(29.3)$ & $44(47.3)$ & $42(30.2)$ & \\
\hline Deficient $(<25 \mathrm{nmol} / \mathrm{L})$ & $115(44.4)$ & $35(37.6)$ & $79(56.8)$ & \\
\hline
\end{tabular}

Data are number (\%) unless otherwise stated.

${ }^{*}$ Kruskal-Wallis, Mann-Whitney or $\chi^{2}$ test as appropriate.

†Median (IQR).

†Length of ICU stay.

§Comparing COVID-19 and influenza A.

IDeath after discharge from ICU.

ICU, intensive care unit; NA, not available; $25(\mathrm{OH}) \mathrm{D}, 25$-hydroxy vitamin D. 
of the $\mathrm{R} m g c v$ package using the default, thin plate regression smoothers. ${ }^{21}{ }^{22}$ The upper limit of smoother dimensionality was set to 9 for all variables, excluding the comorbidity count, where it was set to 7 as this variable was discrete with seven levels. Smoother parameters were estimated with restricted maximum likelihood. $25(\mathrm{OH}) \mathrm{D}$ concentrations were below the LLOD for 92 patients (free) and 2 patients (total) in the COVID-19 cohort. For the regression models, $25(\mathrm{OH}) \mathrm{D}$ values for these patients were imputed as the LLOD for the relevant analyte divided by the square root of $2 .{ }^{23}$ As this is a commonly used but arbitrary method the regression analysis was repeated using 0 and the LLOD as imputed values to assess the sensitivity of the result to this assumption. Effects for categorical covariates are reported as OR; smoothed continuous covariates are reported graphically. Statistical analyses were conducted in $\mathrm{R}$ using the $m g c v$, tidyverse and gratia packages.

\section{RESULTS}

\section{Patient characteristics}

Samples were obtained from 259 people hospitalised due to COVID-19 and 93 people hospitalised due to influenza A. Samples were also obtained from 139 critical illness survivors (prior to the COVID-19 pandemic) at the time of ICU discharge. Patient characteristics, including sampling time after symptom onset, are shown in table 1 . For patients with COVID-19, samples were obtained a median of 3 days (IQR 2-6) after hospital admission. Patients with influenza A were younger, more likely to be female and more likely to have asthma compared with the other cohorts. Receipt of IMV and in-hospital mortality did not differ between COVID-19 and influenza A. The WHO Ordinal Severity Scale scores for people with COVID-19 are shown in online supplemental figure 1 , illustrating that the cohort is representative of the full spectrum of disease severity in hospitalised people. Details on ethnicity were available for the COVID-19 and influenza A cohorts. No differences in total $25(\mathrm{OH})$ D were observed between ethnic groups, but only small numbers of participants were from non-white groups (COVID-19 65 of 259, influenza A 25 of 93; online supplemental figure 2). All samples from people with influenza A were collected between the months of November and February (63.4\% in December), whereas all samples from people with COVID-19 were collected between March and June (67.6\% in April). However, the distribution of total $25(\mathrm{OH}) \mathrm{D}$ measurements did not differ when stratified by month (online supplemental figure 3). Total 25(OH)D concentration was lower in all three patient cohorts when compared with healthy controls ( $\mathrm{n}=36$; online supplemental figure 4), but the healthy control samples were obtained between the months of June and September.

\section{Total 25(OH)D correlates with severity in COVID-19}

The majority of patients with COVID-19 had total 25(OH) $\mathrm{D}$ concentrations indicative of vitamin $\mathrm{D}$ insufficiency
(29.3\%) or deficiency (44.4\%; table 1$)$. Total $25(\mathrm{OH}) \mathrm{D}$ was lower in men than in women (median 26.8 (IQR 14.147.4) $\mathrm{nmol} / \mathrm{L}$ vs median 31.7 (IQR 20.1-63.8) nmol/L, $\mathrm{p}=0.01$ ) and weakly positively correlated with increased age (Pearson's $\mathrm{r}=0.25, \mathrm{p}<0.0001$ ).

When stratified by receipt of IMV as a marker of illness severity, total $25(\mathrm{OH}) \mathrm{D}$ differed significantly with a median concentration of $19.6 \mathrm{nmol} / \mathrm{L}$ (IQR 12.6-32.3) in patients receiving IMV compared with $31.9 \mathrm{nmol} / \mathrm{L}$ (IQR 20.0-58.3) in the remainder of the cohort $(p<0.0001$; figure $1 \mathrm{~A})$. When total $25(\mathrm{OH}) \mathrm{D}$ was stratified by associated vitamin $\mathrm{D}$ status, patients receiving IMV were more likely to be insufficient/deficient (figure 1A). Among patients who received IMV, 64.2\% (43 of 67) were deficient and $26.9 \%$ (18 of 67 ) were insufficient. Total $25(\mathrm{OH}) \mathrm{D}$ concentration was also associated with in-hospital mortality (median $23.2 \mathrm{nmol} / \mathrm{L}$ (IQR 15.4-39.9) in non-survivors vs $29.5 \mathrm{nmol} / \mathrm{L}$ (IQR 17.2-55.4) in survivors, $\mathrm{p}=0.01)$. Total $25(\mathrm{OH}) \mathrm{D}$ concentrations were divided into quartiles and the proportion of patients who received IMV was compared (figure 1B). The lowest quartile $(\leq 17.3 \mathrm{nmol} / \mathrm{L})$ had the highest proportion of patients receiving IMV (43.1\%). The middle quartiles were similar $(26.6 \%$ and $25.0 \%)$, with the highest $25(\mathrm{OH})$ D quartile $(>51.8 \mathrm{nmol} / \mathrm{L})$ containing the lowest proportion receiving $\operatorname{IMV}\left(7.8 \%, \chi^{2} \mathrm{p}=0.0001\right)$.

Obesity is a risk factor for severity and mortality in COVID-19 and can be associated with vitamin D deficiency. ${ }^{15}$ However, there was no difference in total $25(\mathrm{OH})$ D concentration between patients with/without cliniciandefined obesity (online supplemental figure 5). Inflammatory mediator measurements had previously been performed on plasma samples from 66 patients included in this study. ${ }^{24}$ Correlation matrix analysis demonstrated that total $25(\mathrm{OH}) \mathrm{D}$ was not significantly associated with circulating markers of systemic inflammation demonstrated to be involved in COVID-19 pathogenesis (online supplemental figure 6).

Multivariable analyses confirmed that total $25(\mathrm{OH})$ D concentration and vitamin D status (not sufficient) were both independently and negatively associated with receipt of IMV (table 2, figure 2A and online supplemental table 2). Two patients had total $25(\mathrm{OH}) \mathrm{D}$ concentrations below the LLOD; using 0 and LLOD, instead of LLOD divided by the square root of 2 , had no substantive effect on significance of covariates or their effect sizes. Vitamin D status was also independently associated with in-hospital mortality, but total $25(\mathrm{OH}) \mathrm{D}$ concentration was not (online supplemental table 2 and online supplemental figure 7A).

\section{Total 25(OH)D correlates with severity in influenza A}

We then extended these observations to total $25(\mathrm{OH})$ $\mathrm{D}$ concentrations measured in people hospitalised with influenza A. Total 25(OH)D was not associated with age $(\mathrm{p}=0.1)$ or sex $(\mathrm{p}=0.8)$. Similar to our findings in COVID19 , the majority of patients had total $25(\mathrm{OH}) \mathrm{D}$ concentrations indicative of vitamin D insufficiency $(47.3 \%)$ or 


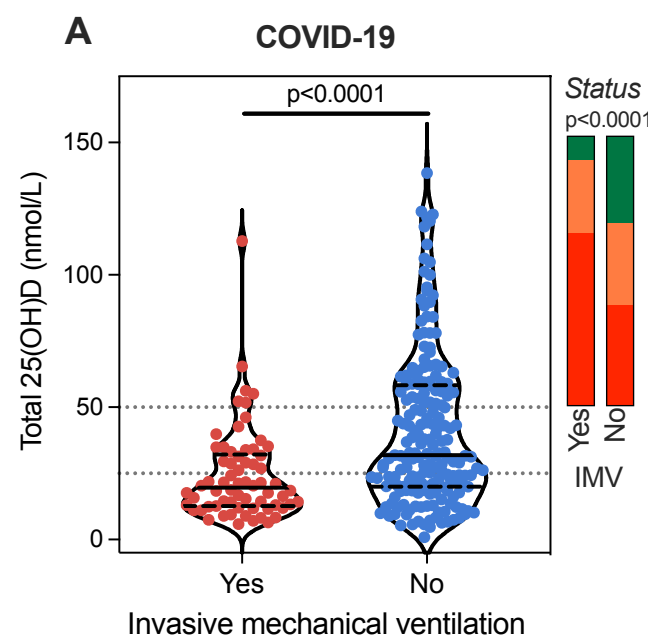

C

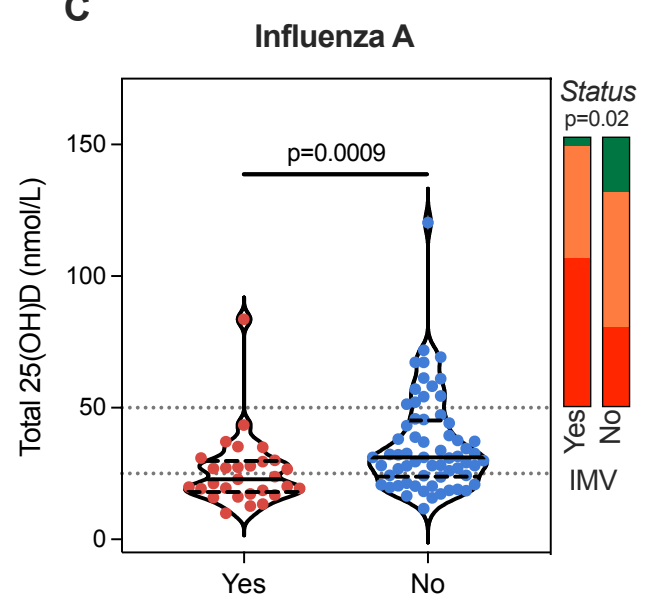

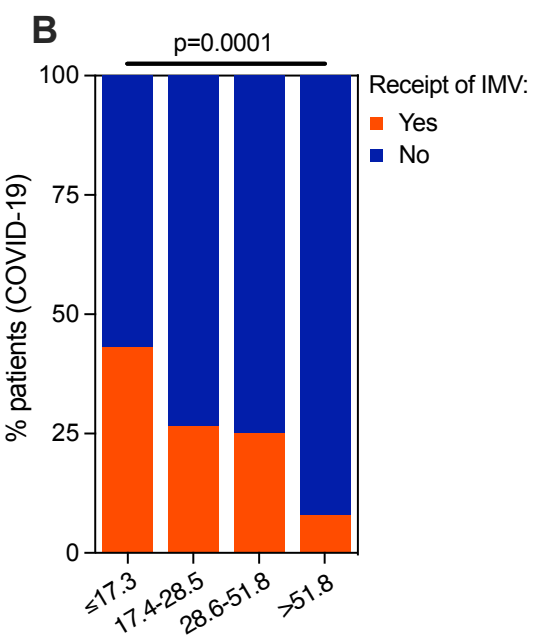

Total $25(\mathrm{OH}) \mathrm{D}$ quartile $(\mathrm{nmol} / \mathrm{L})$

\section{Critical illness survivors}

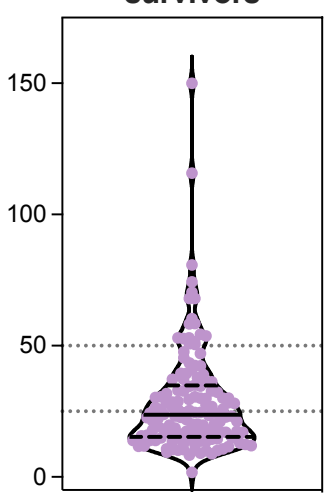

Invasive mechanical ventilation

Figure 1 Total 25(OH)D in COVID-19 and influenza A and in survivors of critical illness. (A) Total 25(OH)D concentrations in patients with COVID-19 ( $n=295)$ stratified by receipt of IMV. (B) Total 25(OH)D concentrations from patients with COVID-19 were divided into quartiles and the proportion of patients who received IMV in each quartile was compared by $\chi^{2}$ test. (C) Total 25(OH)D concentrations in patients with influenza A (from 2009H1N1 pandemic, $n=93$ ) stratified by receipt of IMV. For (A) and (C), groups were compared by Mann-Whitney test. The stacked bar charts represent the proportion of patients in each subgroup with sufficient (green), insufficient (orange) or deficient (red) total vitamin D status, compared by $\chi^{2}$ test. (D) Total $25(\mathrm{OH}) \mathrm{D}$ concentrations in non-selected critical illness survivors ( $n=139$, recruited prior to the COVID-19 pandemic) at the time of ICU discharge. On violin plots of total $25(\mathrm{OH}) \mathrm{D}$ concentrations $(\mathrm{nmol} / \mathrm{L})$, the solid line within the plot represents the median and the dashed lines represent the IQR. The dotted lines on the $y$-axis represent the thresholds for total vitamin $D$ insufficiency $(25-50 \mathrm{nmol} / \mathrm{L})$ and deficiency $(<25 \mathrm{nmol} / \mathrm{L})$. 25(OH)D, 25-hydroxy vitamin D; ICU, intensive care unit; IMV, invasive mechanical ventilation.

deficiency (37.6\%; table 1$)$. When stratified by receipt of IMV, total $25(\mathrm{OH}) \mathrm{D}$ was lower in patients receiving IMV (median $22.9 \mathrm{nmol} / \mathrm{L}$, IQR 18.0-29.8) compared with the remainder of the cohort (median $31.1 \mathrm{nmol} / \mathrm{L}$, IQR 23.8-45.2, $\mathrm{p}=0.0009$ ) and these patients were more likely to be vitamin D insufficient/deficient (figure 1C). Total $25(\mathrm{OH}) \mathrm{D}$ was lower in non-survivors compared with survivors (median $22.1 \mathrm{nmol} / \mathrm{L}$ (IQR 17.6-34.1) vs $29.2 \mathrm{nmol} / \mathrm{L}$ (IQR 20.6-38.5)), but this was not statistically significant $(\mathrm{p}=0.2)$. Multivariable analysis confirmed an independent negative association between total $25(\mathrm{OH}) \mathrm{D}$ and receipt of IMV but not in-hospital mortality (figure 2B, table 2, online supplemental table 3 and online supplemental figure $7 \mathrm{~B}$ ).

\section{Vitamin D deficiency persists in survivors of critical illness}

In survivors of non-selected critical illness, at the time of ICU discharge the median total $25(\mathrm{OH}) \mathrm{D}$ concentration was $22.9 \mathrm{nmol} / \mathrm{L}$ (IQR 14.6-34.6), similar to concentrations in patients with COVID-19/influenza A who required IMV or did not survive. The majority of patients had total $25(\mathrm{OH}) \mathrm{D}$ concentrations indicative of vitamin D deficiency (56.8\%) or insufficiency $(30.2 \%$; figure $1 \mathrm{D}$ and table 1$)$. Total $25(\mathrm{OH}) \mathrm{D}$ concentration was 


\begin{tabular}{lll}
$\begin{array}{l}\text { Table } 2 \\
\text { and outcomes }\end{array}$ & OR & P value \\
\hline Variable & & \\
\hline Total 25(OH)D & & \\
COVID-19: receipt of IMV & & 0.022 \\
Male sex & $2.33(1.13-4.78)$ & 0.487 \\
Comorbidity count* & - & 0.001 \\
Total 25(OH)D* & - & 0.386 \\
Day of illness & - & 0.061 \\
Age & - & \\
Influenza A: receipt of IMV & & 0.27 \\
Male sex $_{\text {Comorbidity count }}^{*}$ & - & 0.15 \\
Total 25(OH)D* & - & 0.016 \\
Day of illness $^{*}$ & - & 0.001 \\
Age $^{*}$ & - & 0.19
\end{tabular}

Free 25(OH)D

COVID-19: receipt of IMV

Male sex $\quad 2.53(1.24-5.314) \quad 0.011$

Comorbidity count $^{*} \quad$ - $\quad 0.605$

Free $25(\mathrm{OH}) \mathrm{D}^{*} \quad$ - $\quad 0.006$

Day of illness ${ }^{\star} \quad$ - $\quad 0.577$

Age $^{*} \quad$ - $\quad 0.053$

COVID-19: in-hospital mortality

$\begin{array}{lll}\text { Male sex } & 2.78(1.25-6.17) & 0.012\end{array}$

Comorbidity count $^{\star} \quad$ - $\quad 0.022$

Free 25(OH)D* $\quad$ - $\quad 0.025$

Day of illness ${ }^{\star} \quad$ - $\quad 0.795$

$\begin{array}{lll}\text { Age }^{*} & - & 0.041\end{array}$

*Smoothed.

IMV, invasive mechanical ventilation; $25(\mathrm{OH}) \mathrm{D}, 25$-hydroxy vitamin D.

not associated with age $(\mathrm{p}=0.7)$, sex $(\mathrm{p}=0.7)$ or length of ICU stay $(p=0.8)$. Measurements were not available from earlier in these patients' illnesses.

\section{Free 25(OH)D correlates with severity in COVID-19}

In patients with COVID-19, we found a strong correlation between free and total $25(\mathrm{OH}) \mathrm{D}$ concentrations $(\mathrm{r}=0.79$, $\mathrm{p}<0.0001$ ) (figure $3 \mathrm{~A})$. Free $25(\mathrm{OH}) \mathrm{D}$ was lower in patients receiving IMV (median $2.4 \mathrm{pg} / \mathrm{mL}$ (IQR 2.4-3.4) vs $3.6 \mathrm{pg} / \mathrm{mL}$ (IQR 2.4-5.7), $\mathrm{p}<0.0001$; figure 3B) but was not statistically different between survivors and nonsurvivors on univariable analysis (median $2.8 \mathrm{pg} / \mathrm{mL}$ (IQR 2.4-4.4) vs $3.3 \mathrm{pg} / \mathrm{mL}$ (IQR 2.4-5.3), $\mathrm{p}=0.2$ ). In multivariable analysis, free $25(\mathrm{OH}) \mathrm{D}$ was negatively associated with both receipt of IMV and in-hospital mortality (figure 2B-D and table 2). Free $25(\mathrm{OH}) \mathrm{D}$ was not associated with plasma inflammatory mediator concentrations (online supplemental figure 6).

\section{DISCUSSION}

Vitamin D insufficiency was prevalent and scaled with severity in patients with COVID-19 and influenza A and insufficiency persisted in survivors of critical illness. As determined by total $25(\mathrm{OH}) \mathrm{D}$ measurement, $73 \%$ of patients with COVID-19, 84\% of patients with influenza A and $87 \%$ of critical illness survivors were vitamin D insufficient/deficient. We demonstrate evidence of a strong association between vitamin D status (insufficiency/ deficiency) during illness and both COVID-19 severity (receipt of IMV) and in-hospital mortality, with relevant confounders such as sex, age, comorbidities and day of illness adjusted for. This observation was replicated in influenza $\mathrm{A}$, but the smaller sample size ( $\mathrm{n}=93$ compared with $n=259$ ) limited multivariable analyses. For the first time, we demonstrate a similar strong negative association between free 25(OH)D and COVID-19 disease severity and mortality. The results from this study extend earlier findings from other observational studies reporting associations between vitamin D status and SARS-CoV-2 infection and COVID-19 outcome. ${ }^{6725-27}$

Vitamin D may beneficially modulate the host response against SARS-CoV-2 via intracrine immune signalling. Vitamin D enhances intracellular pathogen clearance, primarily via the induction of autophagy. ${ }^{28}$ Importantly, the ability of macrophages to produce cathelicidin, which has antiviral activity against influenza virus and respiratory syncytial virus, correlates with circulating $25(\mathrm{OH}) \mathrm{D}$ concentrations. ${ }^{29}$ Although antiviral effects of vitamin D have not yet been demonstrated in vitro for SARS-CoV-2, they have been demonstrated for other bacterial and viral pathogens. ${ }^{30}{ }^{31}$ Consistent with vitamin $\mathrm{D}$ having a role in local immunomodulation, neither free nor total $25(\mathrm{OH})$ D correlated with circulating markers of systemic inflammation involved in COVID-19 pathogenesis (including C-reactive protein, interleukin 6 and granulocytemacrophage colony-stimulating factor ${ }^{24}$ ).

Evidence for the importance of free versus total $25(\mathrm{OH})$ $\mathrm{D}$ in relation to the mechanisms by which vitamin $\mathrm{D}$ exerts antimicrobial and anti-inflammatory functions has been demonstrated ${ }^{32}{ }^{33}$ We now demonstrate that free $25(\mathrm{OH})$ D was negatively associated with COVID-19 severity and in-hospital mortality. Studies directly measuring free $25(\mathrm{OH}) \mathrm{D}$ and immune responses to infection or during critical illness are limited. In a study of 30 critically ill patients, supplementation with high-dose vitamin D increased free 25(OH)D and plasma cathelicidin concentrations. ${ }^{34}$ Another study of 30 patients with sepsis reported similar results when they examined the effects of vitamin D supplementation on bioavailable (combined albumin-bound and free fraction) $25(\mathrm{OH}) \mathrm{D}$ and cathelicidin concentrations. ${ }^{35}$ Together, these findings suggest that low concentrations of free $25(\mathrm{OH}) \mathrm{D}$ may reduce vitamin $\mathrm{D}$-induced antimicrobial and anti-inflammatory response, compromising immune defences.

We found that $30.2 \%$ of patients surviving critical illness and requiring IMV (prior to the COVID-19 pandemic) were vitamin $\mathrm{D}$ insufficient and $56.8 \%$ were deficient. 
Total 25(OH)D

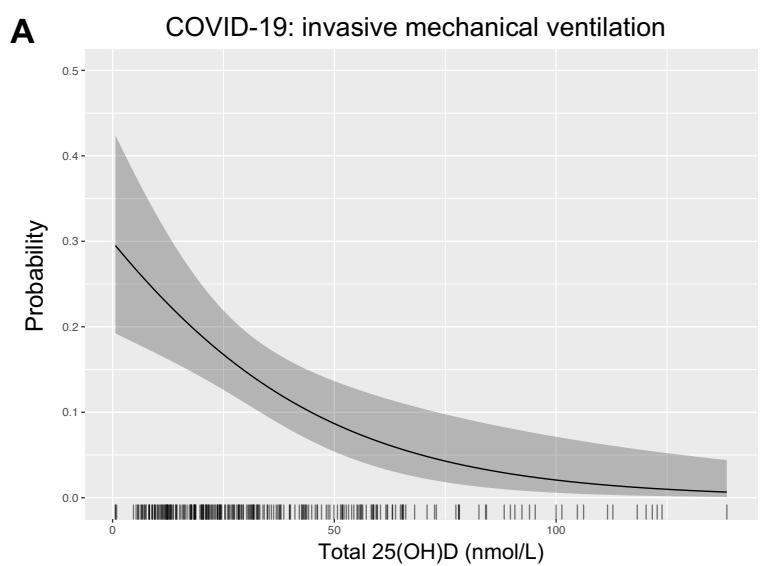

\section{Free 25(OH)D}

C

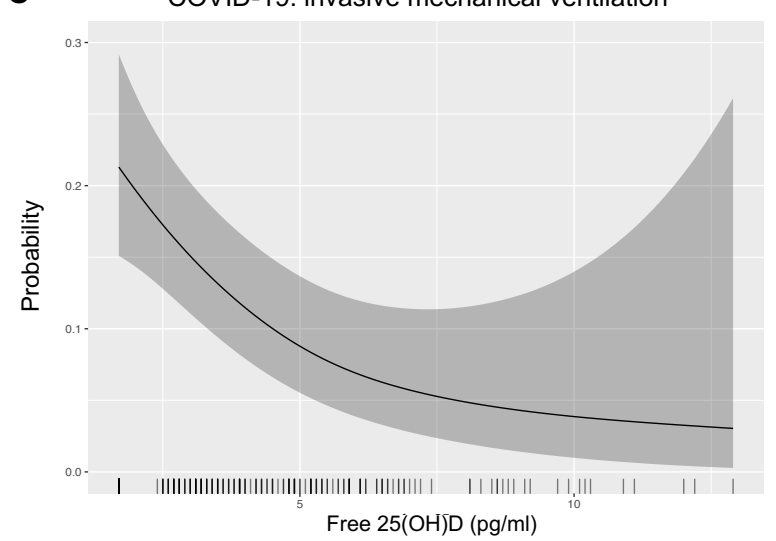

B Influenza A: invasive mechanical ventilation

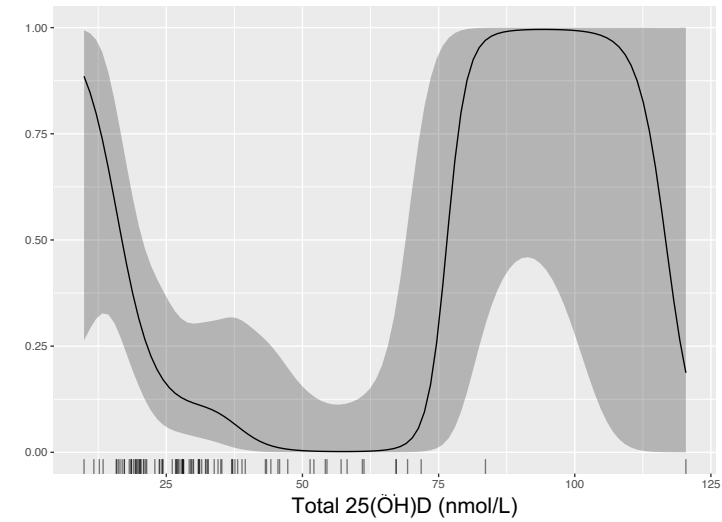

D

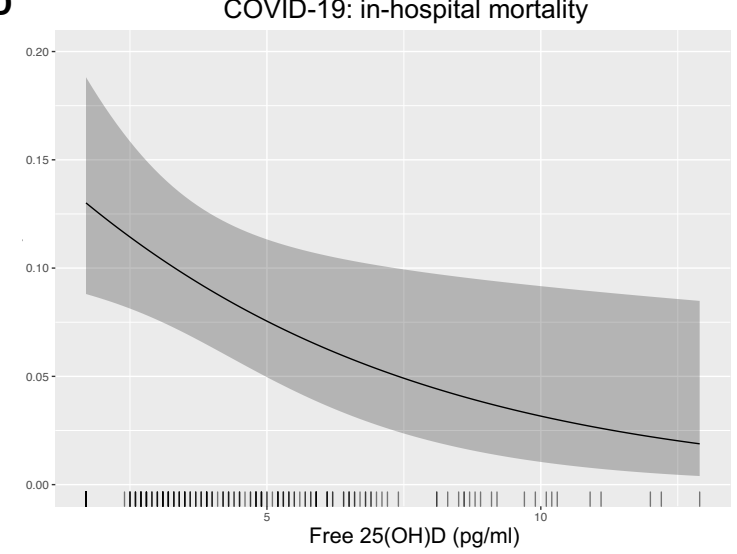

Figure 2 Total and free 25(OH)D and outcomes in COVID-19 and influenza A. Smoothed predicted probability of outcomes (invasive mechanical ventilation (A. B and C) or in-hospital mortality (D)) versus total (A and B) or free (C and D) 25(OH)D concentration (with other covariates at mean values) from the binary logistic regression multivariable models. The grey ribbon represents the estimated $95 \% \mathrm{Cl}$ and the $\mathrm{x}$-axis ticks show the observations. 25(OH)D, 25-hydroxy vitamin D.
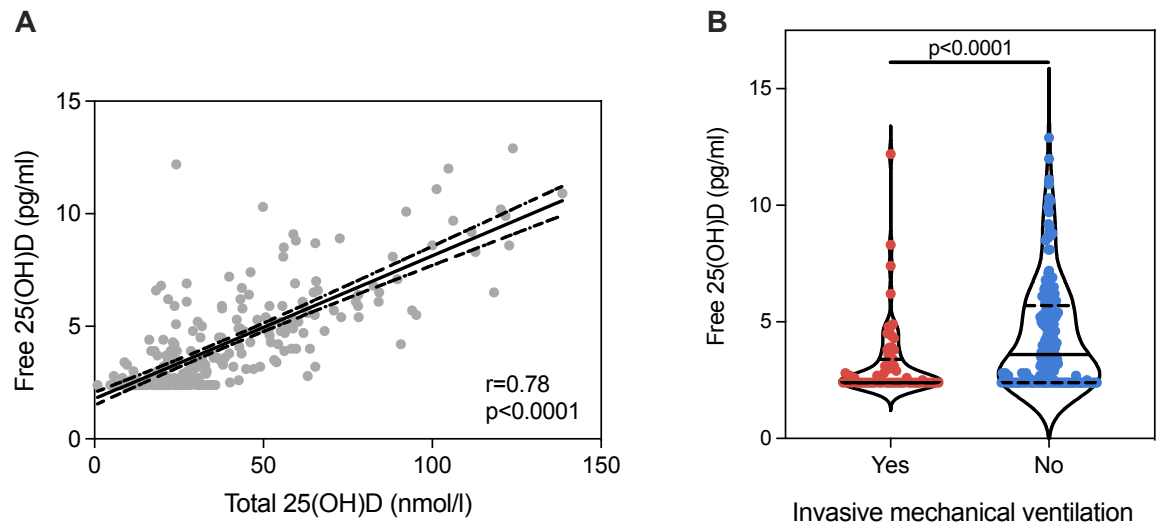

Figure 3 Free 25(OH)D in COVID-19. (A) Simple linear regression line and 95\% Cl (dashed lines) representing the correlation between total and free $25(\mathrm{OH}) \mathrm{D}$ concentrations in COVID-19. (B) Violin plot of free $25(\mathrm{OH}) \mathrm{D}$ concentrations $(\mathrm{pg} / \mathrm{mL})$ in patients with COVID-19 stratified by receipt of invasive mechanical ventilation. The solid line within the plot represents the median and the dashed lines represent the IQR. Groups are compared by Mann-Whitney test. 25(OH)D, 25-hydroxy vitamin D. 
Vitamin D deficiency is common in critical illness, with a reported prevalence of between $40 \%$ and $70 \%$ in observational studies of both adults and children worldwide. ${ }^{3637}$ Although some patients may enter ICU in a deficient state due to pre-existing disease and malnutrition, vitamin D metabolism is dysregulated in critical illness ${ }^{38}$ and concentrations fall rapidly after ICU admission. ${ }^{39}$ The mechanistic link between acute illness and vitamin D deficiency is likely to be multifactorial, including reduced dietary intake/absorption, reduced cutaneous synthesis due to lack of sunlight and wastage due to reductions in vitamin D binding protein. ${ }^{40}$ Furthermore, vitamin D insufficiency/deficiency has been associated with a range of poor outcomes in critical illness. ${ }^{3741-43}$ Vitamin D insufficiency leads to secondary hyperparathyroidism and a concentration of $50 \mathrm{nmol} / \mathrm{L}$ total $25(\mathrm{OH}) \mathrm{D}$ is required for optimum PTH concentrations. ${ }^{44}$ Of the critical illness survivors, $87 \%$ had total $25(\mathrm{OH}) \mathrm{D}<50 \mathrm{nmol} / \mathrm{L}$, which would be associated with secondary hyperparathyroidism and the potential for associated loss of bone mineral density. Critical illness survivors suffer accelerated loss of bone mineral density in the year after ICU discharge (compared with matched controls) and increased 10-year fracture risk. ${ }^{14}$ Our findings implicate vitamin D insufficiency in this process.

There is evidence that vitamin D supplementation can improve circulating total $25(\mathrm{OH}) \mathrm{D}$ concentrations in critically ill patients, ${ }^{34} 3545$ but evidence of a beneficial effect on outcomes is less clear. High-dose vitamin D supplementation in COVID- $19^{13}$ and critical illness ${ }^{45}$ has been shown to increase plasma $25(\mathrm{OH}) \mathrm{D}$ concentrations 7 days post supplementation, but no significant reduction in the length of hospital stay or acute outcomes, including in-hospital mortality, admission to ICU or requirement for IMV, was demonstrated. ${ }^{1345} 46$ Longer-term outcomes such as bone health have not been evaluated. Conversely, two randomised trials reported high-dose $25(\mathrm{OH}) \mathrm{D}_{3}$ (instead of vitamin $\mathrm{D}_{3}$ as in the above-mentioned studies) on admission and then subsequent doses on either days 3 and 7 , then weekly $(\mathrm{n}=76),{ }^{47}$ or days $3,7,15$ and 30 $(\mathrm{n}=838),{ }^{48}$ were less likely to require ICU admission. We identified that vitamin D insufficiency was present early in the course of COVID-19 and influenza A (10 and 7 days after symptom onset, respectively), indicating that timing of supplementation may be an important factor when designing future supplementation studies. We propose that future studies examining effects on disease progression should investigate the effects of vitamin D supplementation given earlier in the course of the disease, closer to symptom onset rather than after hospitalisation. Evidence from an observational study of vitamin D supplementation usage supports this approach. ${ }^{49}$ In a cohort of 8297 people with SARS-CoV-2 test results available, habitual vitamin D supplement intake prior to the pandemic was associated with a reduced risk of a positive test result after correction for known confounders including demographics and comorbidities. Furthermore, despite a decline in vitamin D following cardiothoracic surgery, postoperative outcomes (including organ dysfunction and mortality) are still associated with preoperative vitamin D status. ${ }^{50}$ This suggests that supplementation prior to illness onset can still be expected to improve outcomes despite the fall in vitamin D concentration during acute illness. The longer-term effects of persistent vitamin D insufficiency/ deficiency in survivors of critical illness also require further investigation especially in the context of bone health, which could be independently evaluated using sequential measurement of bone turnover markers and serum PTH.

The current study has several important limitations. The observational design prevents any conclusions about a causal role of vitamin D status in poor clinical outcome being drawn. We cannot exclude the alternative explanation that the differences in vitamin $\mathrm{D}$ status were a consequence of illness severity. Although blood samples were obtained from people with COVID-19 and influenza A as soon after hospital admission as feasible, even these early measurements will still be subject to acute illness-related changes in vitamin D homeostasis. Healthy control data are presented (online supplemental figure 4), but these samples were obtained between the months of June and September, whereas samples from people with COVID-19 and influenza A were obtained between November and June (although no intermonth variation was observed). Data on prehospital or in-hospital vitamin D supplementation were not available. Finally, longer-term follow-up samples to assess vitamin D status in survivors of COVID-19 will be informative.

In conclusion, vitamin $\mathrm{D}$ deficiency/insufficiency was present in the majority of hospitalised patients with COVID-19 or influenza A and scaled with severity, highlighting that reduced concentrations of vitamin D are common to these disease states and distinct patient cohorts. For the first time, free and total $25(\mathrm{OH}) \mathrm{D}$ were studied in COVID-19, demonstrating consistent results. It is not clear whether vitamin D status led to poor clinical outcome or was a consequence of illness severity. Randomised trials will be necessary to determine whether a causal relationship exists between vitamin $\mathrm{D}$ early in the course of the disease and development of critical illness. Since vitamin D deficiency/insufficiency persisted at concentrations expected to disrupt bone metabolism in critical illness survivors, investigation of longer-term bone health outcomes is also warranted.

\section{Author affiliations}

${ }^{1}$ The Roslin Institute and Royal (Dick) School of Veterinary Studies, University of Edinburgh, Edinburgh, UK

${ }^{2}$ Mass Spectrometry Core, Edinburgh Clinical Research Facility, Queen's Medical Research Institute, Edinburgh, UK

${ }^{3}$ Molecular, Genetic and Population Health Sciences, University of Edinburgh, Edinburgh, UK

${ }^{4}$ University of Edinburgh Centre for Inflammation Research, The Queen's Medical Research Institute, Edinburgh, UK

${ }^{5}$ Intensive Care Unit, Royal Infirmary of Edinburgh, Edinburgh, UK

${ }^{6}$ Intensive Care Unit, Guy's and St Thomas' Hospital NHS Foundation Trust, London, UK 
${ }^{7}$ Peter Gorer Department of Immunobiology, School of Immunology \& Microbial Sciences, Kings College London, London, UK

${ }^{8}$ Centre for Tropical Medicine and Global Health, University of Oxford, Oxford, UK ${ }^{9}$ Faculty of Medicine, Department of Metabolism, Digestion and Reproduction, Imperial College London, London, UK

${ }^{10}$ NIHR Health Protection Research Unit in Emerging and Zoonotic Infections, Institute of Infection, Veterinary and Ecological Sciences, Faculty of Health and Life Sciences, University of Liverpool, Liverpool, UK

${ }^{11}$ National Heart and Lung Institute, Imperial College London, London, UK

${ }^{12}$ Department of Medicine, University of Cambridge, Cambridge, UK

${ }^{13}$ Division of Genetics and Genomics, Roslin Institute, University of Edinburgh,

Edinburgh, UK

${ }^{14}$ Tropical and Infectious Disease Unit, Liverpool University Hospitals NHS Foundation Trust, Liverpool, UK

${ }^{15}$ Respiratory Medicine, Alder Hey Children's Hospital, Liverpool, UK

Twitter David M Griffith @Griffith_DM, Manu Shankar-Hari @msh_manu, Charlotte Summers @charlot_summers, Malcolm G Semple @ProfCalumSemple, Peter J M Openshaw @p_openshaw, J Kenneth Baillie @kennethbaillie, Clark D Russell @ clarkdrussell and ISARIC4C Investigators @CCPUKstudy

Acknowledgements The ISARIC4C work uses data provided by patients and collected by the NHS as part of their care and support. We are extremely grateful to the 2648 front-line NHS clinical and research staff and volunteer medical students who collected these data in challenging circumstances; and the generosity of the participants and their families for their individual contributions in these difficult times. Thanks to Joanna Simpson and Patricia Lee, who were involved in sample management and free $25(\mathrm{OH}) \mathrm{D}$ data collection during the analytical process. Thanks to Catherine Duff and Sharon Hannah, who assisted in the health and safety aspects of the project, and to the Clinical Biochemistry Department at Imperial College Healthcare NHS Trust for analysing the samples from patients with influenza in 2011. We also acknowledge the support of Jeremy J Farrar (Wellcome Trust) and Nahoko Shindo (WHO).

Collaborators ISARIC4C Investigators: Consortium Lead Investigator: J Kenneth Baillie. Chief Investigator: Malcolm G Semple. Co-Lead Investigator: Peter JM Openshaw. ISARIC Clinical Coordinator: Gail Carson. Coinvestigator: Beatrice Alex, Benjamin Bach, Wendy S Barclay, Debby Bogaert, Meera Chand, Graham S Cooke, Annemarie B Docherty, Jake Dunning, Ana da Silva Filipe, Tom Fletcher, Christopher A Green, Ewen M Harrison, Julian A Hiscox, Antonia Ying Wai Ho, Peter W Horby, Samreen ljaz, Saye Khoo, Paul Klenerman, Andrew Law, Wei Shen Lim, Alexander J Mentzer, Laura Merson, Alison M Meynert, Mahdad Noursadeghi, Shona C Moore, Massimo Palmarini, William A Paxton, Georgios Pollakis, Nicholas Price, Andrew Rambaut, David L Robertson, Clark D Russell, Vanessa Sancho-Shimizu, Janet T Scott, Thushan de Silva, Louise Sigfrid, Tom Solomon, Shiranee Sriskandan, David Stuart, Charlotte Summers, Richard S Tedder, Emma C Thomson, AA Roger Thompson, Ryan S Thwaites, Lance CW Turtle, Rishi K Gupta, Maria Zambon. Project Manager: Hayley Hardwick, Chloe Donohue, Ruth Lyons, Fiona Griffiths, Wilna Oosthuyzen. Data Analyst: Lisa Norman, Riinu Pius, Thomas M Drake, Cameron J Fairfield, Stephen R Knight, Kenneth A Mclean, Derek Murphy, Catherine A Shaw. Data and Information System Manager: Jo Dalton, Michelle Girvan, Egle Saviciute, Stephanie Roberts, Janet Harrison, Laura Marsh, Marie Connor, Sophie Halpin, Clare Jackson, Carrol Gamble. Data Integration and Presentation: Gary Leeming, Andrew Law, Murray Wham, Sara Clohisey, Ross Hendry, James Scott-Brown. Material Management: William Greenhalf, Victoria Shaw, Sara McDonald. Patient Engagement: Seán Keating. Outbreak Laboratory Staff and Volunteers: Katie A Ahmed, Jane A Armstrong, Milton Ashworth, Innocent G Asiimwe, Siddharth Bakshi, Samantha L Barlow, Laura Booth, Benjamin Brennan, Katie Bullock, Benjamin WA Catterall, Jordan J Clark, Emily A Clarke, Sarah Cole, Louise Cooper, Helen Cox, Christopher Davis, Oslem Dincarslan, Chris Dunn, Philip Dyer, Angela Elliott, Anthony Evans, Lorna Finch, Lewis WS Fisher, Terry Foster, Isabel Garcia-Dorival, William Greenhalf, Philip Gunning, Catherine Hartley, Rebecca L Jensen, Christopher B Jones, Trevor R Jones, Shadia Khandaker, Katharine King, Robyn T Kiy, Chrysa Koukorava, Annette Lake, Suzannah Lant, Diane Latawiec, Lara Lavelle-Langham, Daniella Lefteri, Lauren Lett, Lucia A Livoti, Maria Mancini, Sarah McDonald, Laurence McEvoy, John McLauchlan, Soeren Metelmann, Nahida S Miah, Joanna Middleton, Joyce Mitchell, Shona C Moore, Ellen G Murphy, Rebekah PenriceRandal, Jack Pilgrim, Tessa Prince, Will Reynolds, P Matthew Ridley, Debby Sales, Victoria E Shaw, Rebecca K Shears, Benjamin Small, Krishanthi S Subramaniam, Agnieska Szemiel, Aislynn Taggart, Jolanta Tanianis-Hughes, Jordan Thomas, Erwan Trochu, Libby van Tonder, Eve Wilcock, J Eunice Zhang, Lisa Flaherty, Nicole Maziere, Emily Cass, Alejandra Doce Carracedo, Nicola Carlucci, Anthony
Holmes, Hannah Massey. Edinburgh Laboratory Staff and Volunteers: Lee Murphy, Nicola Wrobel, Sarah McCafferty, Kirstie Morrice, Alan MacLean. Local Principal Investigators: Kayode Adeniji, Daniel Agranoff, Ken Agwuh, Dhiraj Ail, Erin L Aldera, Ana Alegria, Brian Angus, Abdul Ashish, Dougal Atkinson, Shahedal Bari, Gavin Barlow, Stella Barnass, Nicholas Barrett, Christopher Bassford, Sneha Basude, David Baxter, Michael Beadsworth, Jolanta Bernatoniene, John Berridge, Nicola Best, Pieter Bothma, David Chadwick, Robin Brittain-Long, Naomi Bulteel, Tom Burden, Andrew Burtenshaw, Vikki Caruth, David Chadwick, Duncan Chambler, Nigel Chee, Jenny Child, Srikanth Chukkambotla, Tom Clark, Paul Collini, Catherine Cosgrove, Jason Cupitt, Maria-Teresa Cutino-Moguel, Paul Dark, Chris Dawson, Samir Dervisevic, Phil Donnison, Sam Douthwaite, Ingrid DuRand, Ahilanadan Dushianthan, Tristan Dyer, Cariad Evans, Chi Eziefula, Chrisopher Fegan, Adam Finn, Duncan Fullerton, Sanjeev Garg, Sanjeev Garg, Atul Garg, Effrossyni GkraniaKlotsas, Jo Godden, Arthur Goldsmith, Clive Graham, Elaine Hardy, Stuart Hartshorn, Daniel Harvey, Peter Havalda, Daniel B Hawcutt, Maria Hobrok, Luke Hodgson, Anil Hormis, Michael Jacobs, Susan Jain, Paul Jennings, Agilan Kaliappan, Vidya Kasipandian, Stephen Kegg, Michael Kelsey, Jason Kendall, Caroline Kerrison, Ian Kerslake, Oliver Koch, Gouri Koduri, George Koshy, Shondipon Laha, Steven Laird, Susan Larkin, Tamas Leiner, Patrick Lillie, James Limb, Vanessa Linnett, Jeff Little, Mark Lyttle, Michael MacMahon, Emily MacNaughton, Ravish Mankregod, Huw Masson, Elijah Matovu, Katherine McCullough, Ruth McEwen, Manjula Meda, Gary Mills, Jane Minton, Mariyam Mirfenderesky, Kavya Mohandas, Quen Mok, James Moon, Elinoor Moore, Patrick Morgan, Craig Morris, Katherine Mortimore, Samuel Moses, Mbiye Mpenge, Rohinton Mulla, Michael Murphy, Megan Nagel, Thapas Nagarajan, Mark Nelson, Matthew K 0'Shea, Igor Otahal, Marlies Ostermann, Mark Pais, Carlo Palmieri, Selva Panchatsharam, Danai Papakonstantinou, Hassan Paraiso, Brij Patel, Natalie Pattison, Justin Pepperell, Mark Peters, Mandeep Phull, Stefania Pintus, Jagtur Singh Pooni, Frank Post, David Price, Rachel Prout, Nikolas Rae, Henrik Reschreiter, Tim Reynolds, Neil Richardson, Mark Roberts, Devender Roberts, Alistair Rose, Guy Rousseau, Brendan Ryan, Taranprit Saluja, Aarti Shah, Prad Shanmuga, Anil Sharma, Anna Shawcross, Jeremy Sizer, Manu Shankar-Hari, Richard Smith, Catherine Snelson, Nick Spittle, Nikki Staines, Tom Stambach, Richard Stewart, Pradeep Subudhi, Tamas Szakmany, Kate Tatham, Jo Thomas, Chris Thompson, Robert Thompson, Ascanio Tridente, Darell TupperCarey, Mary Twagira, Andrew Ustianowski, Nick Vallotton, Lisa Vincent-Smith, Shico Visuvanathan, Alan Vuylsteke, Sam Waddy, Rachel Wake, Andrew Walden, Ingeborg Welters, Tony Whitehouse, Paul Whittaker, Ashley Whittington, Padmasayee Papineni, Meme Wijesinghe, Martin Williams, Lawrence Wilson, Sarah Cole, Stephen Winchester, Martin Wiselka, Adam Wolverson, Daniel G Wootton, Andrew Workman, Bryan Yates, Peter Young.

Contributors Conceptualisation: EAH, RJM, CDR, LT, PJMO, JKB and MGS. Data curation: EAH, DMG, JD and CDR. Formal analysis: EAH, IH and CDR. Funding acquisition: RJM, PJMO, JKB and MGS. Investigation: EAH, RJM, IH, DMG, AGR, TSW, MS-H, NZH, SGD, KD, PAH, RST, RJS, JD, CS, LT, PJMO, JKB, MGS and CDR. Project administration: SCM, HEH and WO. Data visualisation: IH and CDR. Supervision: RJM, MGS, PJMO, JKB and CDR. Writing - original draft: EAH and CDR. Writing - review and editing: EAH, RJM, IH, DMG, AGR, TSW, MS-H, NZH, SGD, KD, PAH, RST, RJS, JD, CS, LT, PJMO, JKB, MGS and CDR. Validation: EAH, RJM and CDR. Guarantor: CDR.

Funding This work was supported by grants from the National Institute for Health Research (NIHR) (award CO-CIN-01), the Medical Research Council (grant MC_PC_19059) and by the NIHR Health Protection Research Unit (HPRU) in Emerging and Zoonotic Infections at the University of Liverpool in partnership with Public Health England (PHE), in collaboration with Liverpool School of Tropical Medicine and the University of Oxford (award 200907), NIHR HPRU in Respiratory Infections at Imperial College London with PHE (award 200927), Wellcome Trust and the Department for International Development (215091/Z/18/Z), and the Bill and Melinda Gates Foundation (OPP1209135), and the Liverpool Experimental Cancer Medicine Centre (grant reference: C18616/A25153), NIHR Biomedical Research Centre at Imperial College London (IS-BRC-1215-20013), EU Platform for European Preparedness Against (Re-)emerging Epidemics (PREPARE) (FP7 Project 602525) and NIHR Clinical Research Network for providing infrastructure support for this research. LT is supported by a Wellcome Trust Fellowship (205228/Z/16/Z). The MOSAIC study was supported by the Wellcome Trust $(087805 / \mathrm{Z} / 08 / \mathrm{Z})$ and the Medical Research Council HIC-Vac network (MR/R005982/1). PJM0 is supported by an NIHR Senior Investigator Award (award 201385). RJS is funded by a EMINENT GSK-NIHR research training fellowship supported by the Cambridge NIHR Biomedical Research Centre. The RECOVER trial was funded by the Chief Scientist Office Scotland (CZH/4/53 (trial registration number ISRCTN09412438). MS-H is funded by the National Institute for Health Research Clinician Scientist Award (CS-2016-16-011). We acknowledge the financial support of NHS Research 
Scotland (NRS) for the Mass Spectrometry Core, Edinburgh Clinical Research Facility.

Disclaimer The views expressed in this publication are those of the author(s) and not necessarily those of the NHS, the National Institute for Health Research or the Department of Health and Social Care, or other funders.

Competing interests RJM and EAH are part of VitDAL, which provides a 25(OH)D assay service on a not-for-profit basis.

Patient consent for publication Not required.

Ethics approval Ethical approval for the ISARIC/WHO CCP-UK study (COVID-19) was given by the South Central Oxford C Research Ethics Committee in England (13/SC/0149), the Scotland A Research Ethics Committee (20/SS/0028), and the WHO Ethics Review Committee (RPC571 and RPC572, 25 April 2013). Ethical approval for the MOSAIC study (influenza A) was given by the NHS National Research Ethics Service, Outer West London Research Ethics Committee (09/ H0709/52, 09/MRE00/67).

Provenance and peer review Not commissioned; externally peer reviewed.

Data availability statement Data are available upon reasonable request. Data generated by the ISARIC4C consortium is available for collaborative analysis projects through an independent data and materials access committee at isaric $4 \mathrm{c}$. net/sample_access.

Supplemental material This content has been supplied by the author(s). It has not been vetted by BMJ Publishing Group Limited (BMJ) and may not have been peer-reviewed. Any opinions or recommendations discussed are solely those of the author(s) and are not endorsed by BMJ. BMJ disclaims all liability and responsibility arising from any reliance placed on the content. Where the content includes any translated material, BMJ does not warrant the accuracy and reliability of the translations (including but not limited to local regulations, clinical guidelines, terminology, drug names and drug dosages), and is not responsible for any error and/or omissions arising from translation and adaptation or otherwise.

Open access This is an open access article distributed in accordance with the Creative Commons Attribution 4.0 Unported (CC BY 4.0) license, which permits others to copy, redistribute, remix, transform and build upon this work for any purpose, provided the original work is properly cited, a link to the licence is given, and indication of whether changes were made. See: https://creativecommons.org/ licenses/by/4.0/.

ORCID iDs

David M Griffith http://orcid.org/0000-0001-9500-241X

Charlotte Summers http://orcid.org/0000-0002-7269-2873

Clark D Russell http://orcid.org/0000-0002-9873-8243

\section{REFERENCES}

1 Hewison M. Vitamin D and the intracrinology of innate immunity. Mol Cell Endocrinol 2010;321:103-11.

2 Chun RF, Lauridsen AL, Suon L, et al. Vitamin D-binding protein directs monocyte responses to 25-hydroxy- and 1,25-dihydroxyvitamin D. J Clin Endocrinol Metab 2010;95:3368-76.

3 Sabetta JR, DePetrillo P, Cipriani RJ, et al. Serum 25-hydroxyvitamin $D$ and the incidence of acute viral respiratory tract infections in healthy adults. PLoS One 2010;5:e11088.

4 Monlezun DJ, Bittner EA, Christopher KB, et al. Vitamin D status and acute respiratory infection: cross sectional results from the United States National health and nutrition examination survey, 2001-2006. Nutrients 2015;7:1933-44.

5 Dancer RCA, Parekh D, Lax S, et al. Vitamin D deficiency contributes directly to the acute respiratory distress syndrome (ARDS). Thorax 2015;70:617-24.

6 Meltzer DO, Best TJ, Zhang $\mathrm{H}$, et al. Association of vitamin D status and other clinical characteristics with COVID-19 test results. JAMA Netw Open 2020;3:e2019722.

7 Kaufman HW, Niles JK, Kroll MH, et al. SARS-CoV-2 positivity rates associated with circulating 25 -hydroxyvitamin D levels. PLoS One 2020;15:e0239252

8 Papadimitriou DT, Vassaras AK, Holick MF. Association between population vitamin D status and SARS-CoV-2 related serious-critical illness and deaths: an ecological integrative approach. World J Virol 2021;10:111-29.

9 Quraishi SA, Camargo CA. Vitamin D in acute stress and critical illness. Curr Opin Clin Nutr Metab Care 2012;15:625-34.

10 Mathyssen C, Gayan-Ramirez G, Bouillon R, et al. Vitamin D supplementation in respiratory diseases: evidence from randomized controlled trials. Pol Arch Intern Med 2017;127:775-84.
11 Martineau AR, Jolliffe DA, Greenberg L, et al. Vitamin D supplementation to prevent acute respiratory infections: individual participant data meta-analysis. Health Technol Assess 2019;23:1-44.

12 Ganmaa D, Uyanga B, Zhou X, et al. Vitamin D supplements for prevention of tuberculosis infection and disease. N Engl J Med 2020;383:359-68.

13 Murai IH, Fernandes AL, Sales LP, et al. Effect of a single high dose of vitamin D3 on hospital length of stay in patients with moderate to severe COVID-19: a randomized clinical trial. JAMA 2021;325:1053-60.

14 Orford NR, Lane SE, Bailey M, et al. Changes in bone mineral density in the year after critical illness. Am J Respir Crit Care Med 2016;193:736-44.

15 Docherty AB, Harrison EM, Green CA. Features of 20133 UK patients in hospital with covid-19 using the ISARIC WHO Clinical Characterisation Protocol: prospective observational cohort study. BMJ 2020;369:m1985.

16 Dunning J, Blankley S, Hoang LT, et al. Progression of wholeblood transcriptional signatures from interferon-induced to neutrophil-associated patterns in severe influenza. Nat Immunol 2018;19:625-35.

17 Walsh TS, Salisbury LG, Merriweather JL, et al. Increased hospitalbased physical rehabilitation and information provision after intensive care unit discharge: the recover randomized clinical trial. JAMA Intern Med 2015:175:901-10.

18 Griffith DM, Lewis S, Rossi AG, et al. Systemic inflammation after critical illness: relationship with physical recovery and exploration of potential mechanisms. Thorax 2016;71:820-9.

19 Hurst EA, Homer NZ, Gow AG, et al. Vitamin D status is seasonally stable in northern European dogs. Vet Clin Pathol 2020;49:279-91.

20 Sai AJ, Walters RW, Fang X, et al. Relationship between vitamin D, parathyroid hormone, and bone health. J Clin Endocrinol Metab 2011;96:E436-46.

21 Wood SN. Thin plate regression splines. Journal of the Royal Statistical Society: Series B 2003;65:95-114.

22 Wood SN. Fast stable restricted maximum likelihood and marginal likelihood estimation of semiparametric generalized linear models. Journal of the Royal Statistical Society: Series B 2011;73:3-36.

23 Lubin JH, Colt JS, Camann D, et al. Epidemiologic evaluation of measurement data in the presence of detection limits. Environ Health Perspect 2004;112:1691-6.

24 Thwaites RS, Sanchez Sevilla Uruchurtu A, Siggins MK, et al. Inflammatory profiles across the spectrum of disease reveal a distinct role for GM-CSF in severe COVID-19. Sci Immunol 2021;6. doi:10.1126/sciimmunol.abg9873. [Epub ahead of print: 1003 2021].

25 D'Avolio A, Avataneo V, Manca A, et al. 25-Hydroxyvitamin D concentrations are lower in patients with positive PCR for SARSCoV-2. Nutrients 2020;12. doi:10.3390/nu12051359. [Epub ahead of print: 09 May 2020].

26 Panagiotou G, Tee SA, Insan Y, et al. Low serum 25-hydroxyvitamin $\mathrm{D}(25[\mathrm{OH}] \mathrm{D})$ levels in patients hospitalized with COVID-19 are associated with greater disease severity. Clin Endocrinol 2020;93:508-11.

27 Carpagnano GE, Di Lecce V, Quaranta VN, et al. Vitamin D deficiency as a predictor of poor prognosis in patients with acute respiratory failure due to COVID-19. J Endocrinol Invest 2021;44:765-71.

28 Yuk J-M, Shin D-M, Lee H-M, et al. Vitamin D3 induces autophagy in human monocytes/macrophages via cathelicidin. Cell Host Microbe 2009;6:231-43.

29 Liu PT, Stenger S, Li H, et al. Toll-Like receptor triggering of a vitamin D-mediated human antimicrobial response. Science 2006;311:1770-3.

30 Campbell GR, Spector SA. Hormonally active vitamin D3 (1alpha,25dihydroxycholecalciferol) triggers autophagy in human macrophages that inhibits HIV-1 infection. J Biol Chem 2011;286:18890-902.

31 Khare D, Godbole NM, Pawar SD, et al. Calcitriol [1, 25[OH]2 D3] pre- and post-treatment suppresses inflammatory response to influenza A (H1N1) infection in human lung A549 epithelial cells. Eur J Nutr 2013;52:1405-15.

32 Chun RF, Peercy BE, Adams JS, et al. Vitamin D binding protein and monocyte response to 25-hydroxyvitamin D and 1,25-dihydroxyvitamin D: analysis by mathematical modeling. PLoS One 2012;7:e30773.

33 Larner DP, Jenkinson C, Chun RF, et al. Free versus total serum 25-hydroxyvitamin D in a murine model of colitis. J Steroid Biochem Mol Biol 2019;189:204-9.

34 Han JE, Alvarez JA, Jones JL, et al. Impact of high-dose vitamin $\mathrm{D}_{3}$ on plasma free 25-hydroxyvitamin $\mathrm{D}$ concentrations and antimicrobial peptides in critically ill mechanically ventilated adults. Nutrition 2017;38:102-8. 
35 Quraishi SA, De Pascale G, Needleman JS, et al. Effect of cholecalciferol supplementation on vitamin $\mathrm{D}$ status and cathelicidin levels in sepsis: a randomized, placebo-controlled trial. Crit Care Med 2015;43:1928-37.

36 Braun A, Chang D, Mahadevappa K, et al. Association of low serum 25-hydroxyvitamin D levels and mortality in the critically ill. Crit Care Med 2011:39:671-7.

37 Lucidarme O, Messai E, Mazzoni T, et al. Incidence and risk factors of vitamin $D$ deficiency in critically ill patients: results from a prospective observational study. Intensive Care Med 2010;36:1609-11.

38 Czarnik T, Czarnik A, Gawda R, et al. Vitamin D kinetics in the acute phase of critical illness: a prospective observational study. J Crit Care 2018;43:294-9.

39 Amrein K, Christopher KB, McNally JD. Understanding vitamin $\mathrm{D}$ deficiency in intensive care patients. Intensive Care Med 2015;41:1961-4.

40 Lee P. Vitamin D metabolism and deficiency in critical illness. Best Pract Res Clin Endocrinol Metab 2011;25:769-81.

41 Braun AB, Litonjua AA, Moromizato T, et al. Association of low serum 25-hydroxyvitamin $D$ levels and acute kidney injury in the critically ill. Crit Care Med 2012;40:3170-9.

42 Arnson Y, Gringauz I, Itzhaky D, et al. Vitamin D deficiency is associated with poor outcomes and increased mortality in severely ill patients. QJM 2012;105:633-9.

43 de Haan K, Groeneveld ABJ, de Geus HRH, et al. Vitamin D deficiency as a risk factor for infection, sepsis and mortality in the critically ill: systematic review and meta-analysis. Crit Care 2014;18:660.
44 Malabanan A, Veronikis IE, Holick MF. Redefining vitamin D insufficiency. Lancet 1998;351:805-6.

45 Amrein K, Schnedl C, Holl A, et al. Effect of high-dose vitamin D3 on hospital length of stay in critically ill patients with vitamin D deficiency: the VITdAL-ICU randomized clinical trial. JAMA 2014;312:1520-30.

46 National Heart, Lung, and Blood Institute PETAL Clinical Trials Network, Ginde AA, Brower RG, et al. Early High-Dose Vitamin $\mathrm{D}_{3}$ for Critically III, Vitamin D-Deficient Patients. N Engl J Med 2019;381:2529-40.

47 Entrenas Castillo M, Entrenas Costa LM, Vaquero Barrios JM, et al. "Effect of calcifediol treatment and best available therapy versus best available therapy on intensive care unit admission and mortality among patients hospitalized for COVID-19: A pilot randomized clinical study". J Steroid Biochem Mol Biol 2020;203:105751.

48 Nogues X, Ovejero D, Pineda-Moncusí M, et al. Calcifediol treatment and COVID-19-Related outcomes. J Clin Endocrinol Metab 2021;106:e4017-27.

$49 \mathrm{Ma} \mathrm{H}$, Zhou T, Heianza Y, et al. Habitual use of vitamin D supplements and risk of coronavirus disease 2019 (COVID-19) infection: a prospective study in UK Biobank. Am J Clin Nutr 2021:113:1275-81.

50 Ney J, Heyland DK, Amrein K, et al. The relevance of 25-hydroxyvitamin $\mathrm{D}$ and 1,25-dihydroxyvitamin $\mathrm{D}$ concentration for postoperative infections and postoperative organ dysfunctions in cardiac surgery patients: the evidence study. Clin Nutr 2019;38:2756-62. 